\title{
correspondence
}

\section{The health of physical anthropology in Britain}

SIR,-It was with some surprise that we read Bernard Campbell's remarks on the state of health of British physical anthropology under the title "Is British physical anthropology dying?" (19 January, page 196). In other circumstances, a doctor who is unable to answer that question could easily find his competence doubted, particularly if he has not properly examined the patient!

Physical anthropology has been faced with the same financial limitations that have affected all other university departments. Certainly many academics have left for posts abroad, but those who have been appointed to posts in Britain have attracted support for their work.

Dr Campbell suggests that anatomy departments should no longer be the "primary resource" for human palaeontology-we disagree. It is our view that anatomists with human and primate dissection experience are still those best fitted to examine, describe and interpret fossil hominid material. lndeed, turning to Britain today, much of the exciting new fossil hominid material that is being recovered in East Africa is undergoing analysis in our London departments, including all of the Koobi Fora (formerly East Rudolf) hominid remains and a substantial proportion of those from Olduvai Gorge as well as material from another site that is, as yet, unannounced. It may be that this wealth of material is stretching the capacity of those entrusted with its study, but it does not support the conception that human palaeontology in Britain is even poorly, let alone dying.

$$
\text { M. H. DAY }
$$

St Thomas's Hospital Medical School. London

B. A. Wood

Middlesex Hospital Medical School,

SIR,-We read with interest Dr Bernard Campbell's observations on our subject and on our department. We agree with some of his comments and we share his hopes for the future of physical anthropology in the United Kingdom. However, we feel that the overall tone of his writing reflects an imperfect understanding of the nature of the modern study of human evolution. Furthermore, it contains a number of important misunderstandings that may be due simply to his long absence from British academic life.

The main issue on which our views diverge from those of Dr Campbell is the question of what properly constitutes the study of human evolution. Dr Campbell places evolution predominantly in the past and claims that "human palaeontology" is the "most fundamental branch of the science of physical anthropology". This is clearly absurd. The biased selection of skeletal material which has come to us from the past is a necessary source of data on human variation over time. Similarly, biological data from contemporary populations is the source of information on human variation in geographical and social dimensions.

Neither source however, is of the slightest value without a central, theoretical framework within which the data can be interpreted. The fundamental framework of physical anthropology is evolutionary theory and the proper development of this requires several different kinds of study that are not merely ancillary to human palaeontology. The key to a successful evolutionary theory is a correct understanding of variation, both within and between living species and especially in relation to environment. It is also necessary to develop a theoretical model that describes the transmission and distribution of genetic information through time and space.

The evolutionary history of man and of the primates can now be partially reconstructed both through palaeontology and molecular anthropology but evolutionary history is not the whole story of evolution.

Furthermore the evolutionary interpretations of the human fossil record itself depends upon knowledge of principles of systematic zoology, of the morphological, behavioural and genetical variability in natural populations, and of the dynamics of evolutionary processes. Problems arise whenever human palaeontology has lost touch with central developments in evolutionary theory. The proliferation of scientific names for new fossil hominid discoveries is only one example of the effects of the past isolation of human palaeontology from other subjects.

As far as University College London is concerned, we would like to set straight the record. Two of our five teaching staff are predominantly concerned with teaching human and primate palaeontology and functional anatomy. Their status as 'temporary lecturers' does not reflect any low priority assigned to these subjects - it is the result of historical circumstances. We consider that these topics, as well as the study of human and non-human primate behaviour, make a contribution to the study of human evolution equivalent to that of biochemical and population genetics and other subjects. Accordingly, they occupy one half of the students' time during the first two years of the physical antropology programme.

Dr Campbell's brief description of our research is a contracted version of an already condensed account in our departmental handbook. The latter had no space to mention that the study on the 'strength and structure of bone' is intended to clarify locomotor patterns in fossil man, or the palaeontological fieldwork carried out by two of our staff in East and South Africa and in Iran, most recently in 1976. We believe that our researches are relevant to the study of human evolution and that we would be no better placed in other departments.

We would like to add that professional human palaeontologists also work in London at the British Museum (Natural History) and at two London teaching hospitals. Altogether they number more than in any other city in the world. It is true that too many talented physical anthropologists have left for America. This is a regrettable occurrence, but it is not unique to physical anthropology, being primarily duc to the effects of a harsh economic climate in Britain.
We conclude by assuring you that physical anthropology is alive and well, and living in Gower Street.
L. Aiello
F. BRETT
D. A. COleman
T. R. OLSON
H. M. WEYMES

University College, London

SIR,--We were dismayed to read Bernard Campbell's article on the state of physical anthropology in the UK. We consider it presents a totally false picture.

In the first half of this century there were two university teaching posts in physical anthropology in the country. There are at least 16 now, most of them in departments of physical/biological anthropology or anthropology. Further, many universities have established departments of human biology with large commitments to physical anthropology. The subject is also taught and/or researched in various departments of anatomy, in polytechnics and in the British Museum (Natural History).

The Society for the Study of Human Biology has a membership of about 450 of whom about 165 are resident in the United Kingdom. Most of these members teach or research anthropological genetics, growth and development, human ecology, environmental physiology, biological aspects of demography, primatology and palaeoanthropology-all central aspects of modern biological anthropology and all necessary for a proper understanding of human evolution. This hardly seems to us evidence of a dying subject!

We recognise that much of the research in fossil hominids is taking place in departments of anatomy and the British Museum. There are many good reasons for this, particularly the need for an extensive anatomical knowledge in palaeoanthropological research. We should point out, however, that wherever physical anthropology is taught in British universities, palaeoanthropology is recognised as an important component of the courses.

We agree that further expansion of physical anthropology is highly desirable; everywhere there is an increasing demand for it by both undergraduates and graduates. We support Dr Campbell in his view that further recognition of palaeoanthropology is necessary. We feel however, that he could only have written the article as he did through having been away from the dramatic developments in physical anthropology which have occurred in Britain in the last decade.

$$
\begin{aligned}
& \text { A. Bilsborough } \\
& \text { J. P. Garlick } \\
& \text { C. G. N. MaScie-TAYlor } \\
& \text { Pamela D. RaSPE }
\end{aligned}
$$

Department of Physical Anthropology.

University of Cambridge

$$
\begin{aligned}
& \text { A. J. BOYCE } \\
& \text { G. A. HARRISON } \\
& \text { V. REYNoLISS }
\end{aligned}
$$

Department of Biological Anthropology, University of Oxford

$$
\text { E. Sunderland }
$$

Department of Anthropology.

University of Durham 